\title{
Mission Alignment and Operationalization: The Case of the United World Colleges
}

\author{
Angel B Perez ${ }^{1}$ \\ ${ }^{1}$ Educational Studies Department, Trinity College, Hartford, USA \\ Correspondence: Angel B Perez, Educational Studies Department, Trinity College, Hartford, CT, USA.
}

Received: October 28, 2018

Accepted: November 25, $2018 \quad$ Online Published: December 2, 2018

doi:10.5430/irhe.v3n4p55

URL: https://doi.org/10.5430/irhe.v3n4p55

\begin{abstract}
This research study explored how a large, complex global educational organization operationalizes its mission and socializes its constituents to support its mission and values. The study's unit of analysis was the United World Colleges (UWC), a group of complex international schools whose multi-campus and multinational structure shares a values-driven and activist-oriented mission. With an interest in exploring causation, the researcher employed case study methods to understand how this large organization brings its mission to life on a daily basis.

Extensive interviews, observations and document analysis at five units of the organization led to eight themes consistent across all data collected. The research study revealed that the following factors play a significant role in mission operationalization and alignment: (1) The entrance and exit strategy for members of the organization; (2) selection of the organization's members; (3) curricular choice and teaching methods; (4) use and structure of the physical space; (5) programming; (6) residential life; (7) reflection; and (8) simplicity and tangibility of the mission statement.

The study has implications for international schools and organizations keen to create strategic alignment between their mission and daily operations. The findings in the study are generalizable and could inform international organizations in their attempt to implement best practices and make resource allocation decisions to maintain mission fidelity.
\end{abstract}

Keywords: international education, mission, united world college, mission alignment

\section{Introduction}

Most educational institutions employ a mission statement that guides the organization and defines its purpose. Regardless of the level of education they provide, schools are required to have a mission statement for accreditation purposes (Gow, 2009), and even to maintain tax exempt status in the United States (Brinkerhoff, 2000). It is rare to visit the website of a school, college, or university today without finding a section on its mission, values, or purpose. Schools commonly use these to inform their constituents of what they stand for, and in many cases, what makes them different from competitors. Mission statements guide daily work while attracting and retaining its community members. How the mission is brought to life matters deeply to the success of any organization.

In today's educational landscape, a school's institutional mission matters just as much, if not more, than it has throughout history (Boerema, 2009). Educational institutions are growing more complex and the pressure to prove mission alignment and efficiency is crucial for accreditation, fundraising, and grant allocations (Gow, 2009). Schools need to continuously adhere to or reexamine their missions in an effort to understand their organization's performance (Boerema, 2006). Without a clear understanding of performance and mission alignment, there are many factors at risk, including skewed resource allocation (Gow, 2009). Therefore, it is important to understand whether or not there is alignment between the institutional mission and goals (Hirschfield, 2009; Gow, 2009; Hendrie, 1996).

As institutions of education face ever-increasing pressure to allocate their limited resources strategically, create tools to measure the efficacy of their work, and become data-driven in reporting their outcomes, research on best practices will grow increasingly necessary. Schools need to successfully communicate their mission alignment and outcomes for accreditation, fundraising, foundation support, and even to maintain their non-profit status (Brinkerhoff, 2000). A study about one of the most complex mission-driven international organizations provides key guidance into the role of mission, alignment, and operationalization in today's educational landscape. 


\section{Purpose of the Study}

"UWC makes education a force to unite people, nations and cultures for peace and a sustainable future"

UWC Mission - http://www.uwc.org/about_uwc/mission_and_vision.aspx

The purpose of the study was to research and deconstruct how a large, complex, global organization operationalizes its mission and socializes its constituents to support the mission. This study attempted to gain a better understanding of the daily operations of The United World Colleges. The researcher aimed to comprehend the systems and processes the organization has created in an effort to align with its mission. Branson's (2003) study found that informal learning experiences at UWC are influential for students. However, the researcher was interested in understanding how UWC's daily operations work to create those experiences and what areas of the college and the international office contribute to mission alignment. Given the rich history and uniqueness as a system of schools whose reason for being is to promote mission and values, the United World Colleges have a responsibility to maintain fidelity to their mission. They must do so within the complexity of a large multi-campus, multinational organization.

The United World Colleges are a group of secondary international schools in seventeen different countries (Armenia, Bosnia, Canada, China, Costa Rica, Germany, India, Swaziland, Hong Kong, Italy, Japan, Netherlands, Norway, Singapore, Thailand the United States, and Wales) with an international operations office in London. The organization celebrated its 50th birthday in 2013 and represents one of the most unique international school systems in the world. The reason United World College makes for a fascinating study is their historical commitment to the actualization of a mission-driven education. In fact, UWC's main reason for existing is to promote a values-driven education (Tsumagari, 2010): "UWC's stand out as the only schools whose main raison d'etre is the promotion of such values" (Hayden, 2006).

Members of the UWC community refer to UWC as a movement, not just a set of international schools. The mission of the school is in fact the goal of the movement: "to make education a force to unite people, nations and cultures for peace and a sustainable future" (UWC, 2014).

\section{Research Questions and Process}

\subsection{Research Questions}

The following main research questions guide the study: How does UWC operationalize its mission? What structural systems are put in place through the academic, co-curricular, admission, and staffing programs that bring the mission to life? How does it socialize its constituents to support the mission?

\subsection{Unit of Analysis}

The unit of analysis in this research study is not a single UWC campus, but rather, the UWC system as a whole. While individual campuses were visited and highlighted, the goal of the study was to evaluate UWC as a system of international schools that comprise a global organization. Therefore, the study employed single case study research methodology as opposed to a multiple case study approach that analyzes each campus individually.

The independent variables are UWC and its mission, while the dependent variables are the areas of operation that feed into the mission. The researcher employed exploratory case study research methods, whose purpose is to explore causation. "The exploratory case study investigates distinct phenomena characterized by a lack of detailed preliminary research" (Streb, 2009). In addition, "an exploratory case study presents data bearing on cause-effect relationships - explaining how events happen" (Yin, 2003).

\subsection{Site Selection}

While there are many campuses the researcher could have chosen to include in the study, limited time and resources prohibited travel to all UWCs in the system. Thus, the decision to visit four campuses and the International Office was made strategically; in particular, including the International Office (IO) in the study was a key component. The IO is the governing body of the organization and houses staff members who oversee most organizational efforts across nations. The IO houses archival material that dates back to the founding of the organization. In addition, I felt it was important to include campuses that varied in age, size of student body, fiscal resources, cultural context, and geographic location. As a result, the researcher decided to visit the campuses in Wales, the oldest campus with one of the strongest financial resources; Germany, then the newest campus, in the midst of creating campus culture, tradition, and policy; Costa Rica, one of the youngest and smallest campuses with no fiscal endowment; and the Netherlands, a more established campus in the European region with a public-private partnership. 


\subsection{Sources of Data Collection}

Data for this qualitative study were collected through the following sources:

3.5 Individual and Group Semi-structured Interviews with UWC students, alumni, school leadership, international office leadership, and admission selection committee members.

3.6 Ethnographic Observations on four UWC campuses and the International Office added strength to the data collection of the research study. On each of the campuses visited, the researcher attended several classes, sat in on administrative meetings, and observed informal and co-curricular activities. The researcher was on each campus a minimum of two days and a maximum of four.

3.7 Documentation Analysis was conducted from data collected on individual campuses, the International Office, and the UWC documentary found at http://vimeo.com/92744398. These documents included archival information from UWC campuses such as newspapers, newsletters, written school policies and handbooks, historical documents in the International Office, application forms, campus advertisements, alumni magazines, school charter documents, international office memos, and so on. In addition, orientation schedules, congress meeting itineraries, campus orientation PowerPoint presentations, and other school-specific materials were collected on individual campuses. While some of the data were entered directly into qualitative research software for storage, coding, and analysis, (Nvivo) other data was organized and summarized manually.

\subsection{Coding}

The researcher used various stages of coding methodology in order to engage in "sense-making" (Paull et al. 2013) of the various forms of data collected. The first five interviews and observations collected were manually coded twice. Recognizing that "rarely will anyone get coding right the first time," (Saldaña, 2013) The researcher engaged two manual levels of coding before uploading the interviews, observations, and document collections into Nvivo software for electronic coding and storage. Finally, the researcher used codeweaving methods to help make connections between the data. "Codeweaving is the actual integration of key code words and phrases into narrative form to see how the puzzle pieces fit together" (Saldaña, 2013).

\subsection{Analysis}

In order to answer the research question, the researcher engaged as many aspects of the UWC operation as possible. The site selection process was deliberate and sought to include economic, geographic, and historical diversity in the sample. The researcher was able to visit five units of UWC, interview several other campus heads, and engage alumni and board members from campuses all over the globe. Visiting more campuses would have delivered marginal results, as these five units of UWC are a strong representative sample of the organization. Incredible access to the daily life and operation of UWC afforded the researcher the ability to analyze documents from individual campuses and the International Office and conduct observations on each campus, which added to the rich collection of data for analysis. It allowed for a better understanding of campus interactions, programming, and the physical structure, and framed the organization in a historical context. The interviews provided an opportunity to understand the experience of students, alumni, and staff of various generations of the UWC experience. This allowed the research to include not only recent UWC experiences, but also those of graduates from several decades ago. It was important to include experiences that span the history of the organization when seeking consistency and themes in mission alignment.

Interviews, ethnographic observations, document analysis and coding were all used and triangulated to make sense of the data and find themes across the various campuses. Once the data collection was complete, I then used Nvivo software to triangulate the information. Data triangulation involves using different sources of information in order to increase the validity of a study (Golafshani, 2003; Olsen, 2004). The researcher compared and contrasted the interviews, observations, document analysis, and other documentary evidence with the goal of finding patterns, themes, contradictions, and new variables that needed further investigation. The researcher began to find themes and patterns consistent across campuses, including the International Office, which highlighted the systematic formal and informal efforts that UWC puts in place to operationalize its mission. The researcher thus began to develop findings and conclusions.

\section{Research Findings}

Eight major findings emerged in this study. 


\subsection{The Entrance and Exit Strategy for Community Members Matters}

How students are informed about the UWC mission and what strategies the Colleges put in place as students exit the organization is vital to helping inculcate mission fidelity. All of the Colleges visited have an extensive orientation program in which students learn about the mission and history of the organization. However, the mission is not necessarily explained in a traditional format. While most of the heads of each school give an opening speech or presentation, it is the formats they use to help convey the mission that is important. When interviewed, most administrators and school leaders mentioned the orientation program and how they try to use their presentations in a strategic and emotional way to reach the students.

From the moment students arrive on the campus for the first time they are introduced to the mission of the organization in formal and informal ways. Each school head gives a speech at the opening of orientation that expresses the urgency of the mission and how special the students are for having been chosen to uphold this mission. Many of the students and alumni interviewed distinctly remember these speeches and the format in which they were presented. 56\% (10 out of 18) of alumni and 50\% (9 out of 18) of students interviewed mentioned a specific experience with their orientation programs when asked to identify how they came to understand the mission of UWC. Several of the interviewees expressed the power of their orientation programs in this way:

I remember my school head giving us a presentation about the mission and values of the school - and then he told us about the competencies - which is how you actually live the values. He shared alumni stories and what they were doing with their lives. We even got deep into a discussion about what Peace is and how you deconstruct it. If our mission was to create a peaceful world, what did that mean? I loved the fact that we weren't just told what the mission was, but we got a chance to discuss and debate it from day one. From that moment on, I knew it was my responsibility to live up to this grand mission (Alumnus, Costa Rica).

I remember our deputy school head making a presentation about what it means to be UWC. I was sort of fading out until he asked us what we would do if we won 55,000 pounds. He took us through this process where we eventually realized not only how privileged we were to be here, but what a grand responsibility we have to fulfilling the UWC mission (Alumnus, Wales).

The way students are oriented is critical to ensuring their commitment to the mission during their two years on campus, but it's the exit process that encourages them to dedicate their lives to the mission. 66\% (12 out of 18) of alumni interviewed were able to recall a speech, activity, or exercise they took part in that made them feel a great sense of commitment to the mission after graduation. UWC leaders try to instill a sense of responsibility to the mission for life.

While the campuses use varying rituals or traditions to "exit" their students in different ways, they all are engaged in intentionality through reminding students that it is their responsibility to carry forward the UWC mission. The Netherlands campus has students create an art project for the school. A part of that project will remain at the school while each student takes a piece with them. The intention is to remind the students that they have a part in this global mission. Costa Rica holds talent shows when the parents arrive for graduation and includes parents in conversations about living the UWC mission. School heads and board members include the mission in their speeches and give examples of concrete ways current alumni are living up to it.

How we exit students from the UWC experience is very important - and we think about it deeply. If we are a movement, and not just a set of schools, we need to create systems and processes in place that are going to remind students of how important it is to live a UWC life. That starts at graduation. It's also important to leave students feeling a sense of responsibility to the movement. This is how we recruit National Committee volunteers, UWC advocates, recruiters, etc. (UWC International Office staff member).

\subsection{Selection Processes Matters}

Who you invite to become a member of your community and how you invite them is a key factor for mission alignment. This process includes not only student selection, but that of staff and faculty as well. The United World Colleges has a unique system of selecting students. The Colleges do not recruit students directly; rather, there are 150 National Committees around the globe. These committees are made up of volunteers, many of whom are alumni, based in their home countries. The National Committee selection process is dependent upon hundreds of volunteers around the globe willing to evaluate applications, raise funds for student scholarships, and run a camp every year for prospective students to attend in order to be interviewed.

The National Committee camp and training schedules collected for this study show an incredible amount of variance in the ways in which students are selected and what kinds of processes they must engage during their admission 
process. Some students attend camps, while in countries that can't hold camps, admission depends solely on applications and in some cases Skype interviews.

While each National Committee has a slightly different way of selecting students that is culturally appropriate, there are common themes that all 150 committees look for. "Essentially, the members of the National Committees are told they are responsible for carrying out the mission of UWC through the selection process" (Turner, interview, March 12, 2013). Some of the committees have students create cultural skits or talent shows or engage in debates about international issues, or provide difficult tasks for students to achieve while purposefully having to work together. Many committees immediately impart the importance of representing one's country when students arrive at a UWC. $44 \%$ ( 8 out of 18) of the students interviewed recalled being asked a question about how they would represent their country if chosen to be a UWC student. The committee selection members look for various things that are in alignment with the mission:

We give kids a topic on immigration to discuss and debate. Then we put them in charge of cooking that night's meal - and they have to figure it out. Even though they are from the same country, a lot of these students come from different villages with varying traditions. How are they going to manage creating a meal together and break through the barriers? In the selection process, we are trying to give them a mini-UWC experience (National Committee member, Paraguay).

It was actually the admissions process that helped me understand what UWC was all about. You could read about the mission on a piece of paper, but when you are thrust into a 4 day camp in challenging and uncomfortable situations and you have to figure out conflict with others, you realize that this is so much bigger than just applying to a school (Alumnus and National Committee member, Kosovo).

How students are selected is key to upholding the mission, but how staff is selected is just as important. All interviewees in charge of hiring staff members mentioned the importance of considering mission and values when hiring. They firmly believe that it is vital to invite members into the community who are passionate about the mission and values of the institution, and finding ways to ask this in the interview process is crucial. The following are some of the ways campus leaders approached recruiting with the UWC mission in mind:

When I recruit faculty, I directly ask them to reflect on the mission and values of UWC. I also make sure to include current students in the selection process. I ask kids to talk about their UWC experience and what it means to them. Kids can tell when adults are not being genuine about the mission, but this tactic is a double-edged sword. If the people interviewing are not very "UWC" they will weed themselves out as they hear the kids talk (Administrator, Costa Rica).

When I hire, I ask potential employees to list examples of how they have engaged UWC's mission in the past. I want to hear examples of how they have engaged sustainability, or conflict management, etc. (Administrator, Netherlands).

$73 \%$ (11 out of 15) of the administrators interviewed believed that how they engage candidates in the hiring process is vital to upholding the mission of UWC. They mentioned specific questions they ask or how they set up the day of the candidate's visit as a strategy to recruit mission driven employees. For them, the hiring process is not only a recruitment tool, but also a retention tool. Those that join UWC for the mission and values tend to stay and dedicate a big part of their lives to it: "I'm living proof. I came to UWC for a job. I've stayed a long time because of the values. It's who I am" (Dillon, interview, March 12, 2015).

\subsection{Curricular Choice and Teaching Methods Matter}

As an academic institution, aligning mission with curriculum is extremely important, and how the faculty members help students make the connection between the two is vital to mission alignment. UWC students engage in one of the most rigorous global curricula, the International Baccalaureate (IB). The IB is a curriculum founded in Switzerland in 1968 by international educators interested in creating a global curriculum that would help students from all over the world prepare for admission to university, while also promoting international values and peace efforts across the globe. The curriculum advocates international-mindedness, and IB defines it as understanding and respecting another point of view without necessarily accepting it, yet learning where it comes from and developing empathy, not just knowledge (IB World, 2008). Given the alignment between the mission of UWC and the mission of IB, UWC was one of the first adopters of the curriculum in the 1960s (Peterson, 2003).

While the IB offers traditional courses like English, math, and history, it also offers courses unique to the curriculum, including a course titled Theory of Knowledge (TOK). This course challenges students to consider how they know 
what they know, and to question knowledge itself and where it comes from. A TOK teacher in the Netherlands stated:

TOK is essential to the mission of UWC. If we want students to become change makers, we need them to question everything and think critically about the world around them. TOK is hard for students because it shakes their reality. Sometimes when students realize that the beliefs they hold are not necessarily theirs, they are the ones they inherited, they feel naked.

A student in Wales agreed: "Theory of Knowledge blew my mind away. I realize I know nothing and must question everything. If I am going to have an impact in this world, I need to develop my own beliefs based on knowledge, not hand me down opinions."

While the IB curriculum is keenly aligned with the UWC values, it is the ways in which teachers use the curriculum and make daily connections to these values that helps students engage the mission fully. During a visit to an English class in Germany, the researcher sat through student presentations about how the media covers human rights issues. While this was not a requirement from the textbook, this was the assignment format the teacher chose. In an interview with the teacher, herself a UWC graduate, she stated:

It's my job to help kids make the connections between what we are learning in class and the UWC mission. I could've had them look up any articles the media covers, but we had just had a community presentation and discussion on human rights. I decided to weave that topic into the course. I get the sense a lot of teachers do this here. We constantly adjust our teaching to be in line with mission-central experiences."

Of the teachers interviewed, $69 \%$ (11 out of 16) mentioned intentionality when trying to shape their classroom experience based on the values of UWC. They kept the mission in mind while choosing which topics to cover, debates to raise, videos to present, or homework to assign.

During a visit to a Theory of Knowledge class in Wales, it was clear that the teacher was trying to bring content that was central to the mission of UWC into his lesson. The teacher used current examples of what was happening in the home countries of his students to try to bring the lesson to life. He would give a brief lecture and provide examples of how other countries are addressing these issues, then ask the students from those countries to comment. In an interview afterwards, he stated:

The way to keep mission on the mind is to remind students that what they are learning here means something in the real world. If I talk about sustainability I want them to have a practical angle and understand the issues in their own country so that when they go back, they know how to use the mission, not just talk about it (Smith, interview, March 10, 2015).

On the Netherlands campus, a Theory of Knowledge teacher added:

Teaching at a UWC is like flying by the seat of your pants. You are constantly changing your lesson plan because of something that happens around the world. For example, if a nation is bombed, we probably have someone in class from that nation. We have to weave the event into our coursework - not just because it's part of the mission, because we have to honor the fact that someone in our classroom is affected by it (White, L. Interview. March 17, 2015).

\subsection{The Physical Infrastructure Matters}

If a community is going to spend the majority of their time in a physical space, that space needs to represent the mission and values of the institution. While most of the community members interviewed did not mention the physical infrastructure, extensive observations and conversations on campus led me to understand the important significance of aligning your physical space with your mission.

No matter which UWC campus I visited, I was struck by the fact that upon arrival, I immediately got a sense of what the schools stood for, as signs displaying cultural awareness issues adorned the walls. I observed each of the campus' physical spaces and took photos of public areas, where I saw constant reminders about students' responsibilities towards the environment. These signs can be found in the lobby, classrooms, and even the bathrooms. All of the campuses host extensive recycling programs, and some had more complex options including buckets for recycling batteries, composting stations, and food waste management. The campus in Germany is taking its efforts a step further. They have housed sheep on campus and plan to bring bees for students to care for and manage the honey, and are considering purchasing solar panels that students will learn to install. "We can't just tell kids what our mission is and hope that they will adhere to it. We have to show them. The UWC mission has to be everywhere - in 
the classroom, the residence hall, the dining hall - and yes - even all over the walls in the bathroom. If you come to UWC, there is no escaping this" (Kellner, interview, March 16, 2015).

All of the campuses have a statue or painting of Nelson Mandela proudly displayed at the entrance. Nelson Mandela once served as president of UWC and has long stood for the mission and ideals of the institution. Some of the campuses have the UWC mission displayed on the walls of the residence halls or academic buildings. All of the campuses display flags from different nations, and Wales takes this one step further. There is a massive Welsh flag displayed on top of the castle; however, every time a different country is having an independence day, national holiday, or celebration, the Welsh flag is removed and that nation's flag is displayed. "Symbolism matters. We need to create physical reminders of the mission and how to embrace it. The changing of the flag is one of the ways we do it" (Lush, interview, March 10, 2015).

The flags appear to be taken very seriously by students. On some of the campuses visited, the researcher observed students wearing their nation's flag during the day as a cape, while others either hung them outside of their residence halls or used then as a display or divider in their rooms. Students at UWC want to wear their culture and national identity on their sleeves. They take every opportunity to showcase their nation.

The campus dining halls change the meals they serve during culture weeks to represent the foods of the countries being celebrated. The researcher also noticed that all of the dining halls served very healthy food and did not display the traditional sugary sweets that other institutions serve teenagers. In Germany, dinner was an incredibly light meal that many would mistake for breakfast.

Our dining hall tries to remind us of how to live a healthy lifestyle. Before I came here, I would eat really heavy meals at night, but I didn't realize what damage that could do to me. Now I'm in Germany and we eat very light at dinner and don't consume many sweets. A healthy lifestyle is part of our values and I'm learning how to do it here with the help of the dining hall (Masquini, interview, March 16, 2015).

The way campuses use their physical space can have a powerful impact on how students engage the mission. "I remember stepping onto the campus in Mahindra and starting to get what UWC was all about. Everywhere I looked there were international flags, composting stations, recycling bins, Nelson Mandela reminders, etc. I knew this place had a very distinct mission, and I was going to be surrounded by it every day" (Alumnus, India).

\subsection{Programming Is Key to Mission Alignment}

The kind of programming and extracurricular activities offered at a school can have a significant impact on the community regarding alignment with the mission of the organization. Spending time on each campus allows one to witness how the campuses are filled with daily programming that represent the mission. From sustainability council meetings, to lectures on social justice, to conferences on peace, spending a few days on a UWC campus gives visitors the opportunity to experience the mission on a daily basis. UWC campus leaders have thought extensively about creating mission-centric programming. The campuses all share several programs in common:

(A) Culture Weeks. Several weeks each year are dedicated to the celebration of countries from a particular region of the world. The students from this part of the world create events on campus for other students to learn about their cultures. The students hold talent shows, lectures, dances, show movies, etc., and in addition, the students advise the dining halls on what kind of food to serve that week. If the cultures represented are in conflict zones, these issues are addressed. Sometimes outside speakers are brought in to discuss conflict, such as in the Middle East for example, while teachers try to supplement their lessons with peace and reconciliation material. "The point of the culture weeks is not just to have a symbolic song and dance of the nations represented, it's to also understand what the challenges are in the region and help students understand how they can use the mission of UWC to commit to engaging those challenges" (White, interview, March 16, 2015).

(B) Project Weeks. All students at UWC select a project to work on for a week outside of campus. Some students will do social service and volunteer activities, while others will travel to a different country to explore mission-related issues. These project weeks are planned in an effort to support the mission of the institution. For example, when I visited the Netherlands campus, the students had just returned from a trip to Ireland to study the history of peace and reconciliation efforts in that part of the world. Some students will go on trips to learn how to lead more sustainable lives or use technology for renewable energies. The campus in the Netherlands, which houses an elementary school, has its younger students become involved in a river cleaning project or engage in projects that help them to understand how to compliment and support one another instead of putting each other down. This is an effort the faculty feel can lead to students understanding the importance of peace. 
(C) Conferences. Most of the campuses host student-led conferences around themes that feed into the UWC mission. Most recently, the campuses in the study hosted conferences on Peace, Sustainability, the Model United Nations Debate, and Theory of Knowledge. Two of the campuses also hosted TEDX. "One of the most important things we do is have students become responsible for putting forth the programming. It teaches leadership skills, but they also have to think deeply about mission-related topics like Peace and Sustainability. They have to put on an entire conference. It's inspiring to watch" (Howe, interview, March 19, 2015).

Of those interviewed, $83 \%$ (15 out of 18) of students and $72 \%$ of alumni (13 out of 18) mentioned certain aspects of the programming on campus as significant when trying to recall how the mission came to life on campus. All of the programming mentioned by interviewees were systems intentionally built into the educational experience by the UWC campus. The experiences mentioned most by students and alumni were community assemblies/conferences $(61 \%$, or 22 out of 36$)$ and culture weeks $(53 \%$, or 19 out of 36$)$.

Finally, UWC has created rituals and traditions that promote the mission and, according to students and alumni, have had a powerful effect on students. At UWC USA, flags are passed down from the graduates to the first-year students. In Wales, the students wear sweatshirts with the name of their residence halls and what country they are from; students proudly wear them and want to display their country on their sweatshirts every day. In Costa Rica, the students all get together once every few weeks late at night to engage in a "Tim Tam Slam." This is an activity where the students go around the table and tell stories of how they are doing and how the UWC experience is impacting them. There are no adults in the room and students find it very moving. "It's one of the things I remember the most about my time in Costa Rica. To be in a room late at night with your friends and talk about how this experience is impacting you, to share our goals of how we want to contribute to the mission of UWC, it's very powerful" (Alumnus, Costa Rica).

UWC International also creates traditions that keep alumni engaged in the mission of UWC for life. For example, every five to six years they hold a Congress, a working conference where all members of the UWC constituency gather to talk about current issues as they relate to UWC and to chart the path for the future of the organization. Every September $21^{\text {st }}$ is UWC Day around the world. This date also coincides with World Peace Day, and alumni spend time volunteering or orchestrating projects that represent the mission of the organization. "We are trying to create traditions and rituals not just on the campuses, but also for graduates around the globe. If UWC is a movement, we have to put systems in place to constantly remind members of their responsibility to it" (Eskelund, interview, March 12, 2015).

When asked how the mission came to life during their time at UWC, 47\% (17 out of 36) of students and alumni mentioned a campus or system-wide tradition as the most memorable. Of those 47\%, 59\% (10 out of 17) highlighted that the traditions they felt most represented the UWC values were the ones that took place when adults were not present, such as the Tim Tam Slam in Costa Rica or Candle Nights in the Netherlands. One student noted, "This is when you realize we are passionate about the mission and values of UWC. We are not doing it because of an assignment or something a teacher is making us do, it's because we believe in it."

\subsection{Residential Life Matters}

For residential schools, how an organization structures its residential life program can be a powerful way to operationalize the mission. All of the alumni interviewed stated that the ability to live with such a diverse group of people was one of the most powerful aspects of their UWC experiences. When asked how the mission of UWC comes to life on a daily basis, $100 \%$ of students and alumni immediately pointed to the residential program, particularly the fact that they have to break through language barriers and figure out how to live and work with people from unfamiliar cultures and traditions. Some of the interviewees describe their experiences in the following manner: "In a way, UWC forces culture shock. You are shocked by people's beliefs, practices and behaviors. When you are living in such close proximity, it forces you to recalibrate" (Alumnus, Wales).

"The greatest connection to the mission I felt was living with other girls from different parts of the world in the same room. We had to figure out everything from our traditions of waking up to solving conflict. If something was bothering me I couldn't just walk away, because I lived with these people. We were forced to understand each other and figure out ways to make peace - and we sometimes had to do it with language barriers" (Maastricht Alumnus).

"I still remember the smell of the first black guy I ever met. I had never met a black person before, and now I was living with one. I lived in such a bubble. Different became normal and what I didn't understand or 
consider 'normal,' I was forced to investigate. It was a very powerful way to see the UWC mission coming to life every day" (Wales Alumnus).

The residential life program at UWC is created with the mission in mind. "We recruit the tension pairs. We will take kids from Israel and Palestine and Kosovo and Serbia and we put them together in the same room, or on the same floor. They have to figure it out" (Howe, interview, March 19, 2015).

According to the residential life coordinator at Maastricht, the goal of putting students in the room is to create as much tension as possible, and he won't accept any requests to change a student's room if conflict arises. Each student in the room comes from a different nation, culture, socio-economic class or tradition. They also try to place students struggling with different languages together.

We make it very challenging, and they have to figure it out. When they come to us with issues of conflict, we remind them of the mission of UWC and that this is the first step in making the world a more peaceful and sustainable place - learning how to solve conflict. I remind them that if they were in a conflict zone in another country, they would have to work through these issues. (Srivatsava, interview, March 19, 2015).

\subsection{Reflection Engages the Mission}

Of the students and alumni interviewed, 61\% (22 out of 36) mentioned reflection as a way that the UWC mission was kept active in their minds throughout their time on campus and post-graduation. Having community members participate in reflection exercises helps keep mission constantly on the minds of the constituency. UWC originally had students reflect only as a requirement for the International Baccalaureate; students had to reflect on their CAS (Community, Action, and Service) activities and keep a portfolio of these reflections. However, UWC educators realized that having students reflect on other aspects of their UWC experiences helps keep them engaged in the mission. Students submit reflections to the faculty about Project Week, orientation experiences, the faculties program (Wales) or how they have engaged the competencies (Costa Rica). The tutor groups at most campuses are given exercises to help them reflect on their UWC experiences, but the faculty on the Netherlands and Germany campuses spoke about them most directly.

I find that the tutor groups is when we spend the best time reflecting on the UWC experience and how students are living up to the values. Sometimes if I ask kids to write this down, they see it as an assignment and don't take it as seriously, but when we meet in our tutor groups over dinner in a relaxed setting, some very powerful reflections come out of it. I can literally see the mission working (Teacher, Germany).

While there are formal reflection activities assigned by each school, students on each campus have created their own reflection traditions that do not include adults. Each student asked to further describe why reflection was a significant part of their UWC experience pointed to the power of the tradition:

I know I have to reflect for the IB and in my tutor groups. That's all fine and well, and don't get me wrong, I get something out of it - but sometimes it feels like another homework assignment. The best reflection is 'Candle Night.' This is where students get together late at night without adults. We light a candle and everyone has to go around the room sharing a personal story, reflect on what is happening here at UWC or just in their lives. It's such a powerful experience and I learn so much from my fellow students. I always walk away feeling like wow, UWC really is a force for good. The fact that we can all get together despite our backgrounds and differences and share these kinds of powerful experiences is just the first step in changing the world (Student, Netherlands).

\subsection{Simplicity and Tangibility of Mission Is Key}

The simpler the wording of a mission, the easier it is for community members to comprehend. The more tangible it is, the easier it is for community members to know how to live up to it. In a 2005 board meeting held in Singapore, the Chair of the UWC International Board, Christian Hodeige, brought a motion to simplify the mission statement. Prior to this, the mission statement was long, wordy, and very difficult to understand. "The mission statement was so long and lofty most people probably could not recite it. We decided it was time to simplify the mission so it can be stated in one sentence, and everyone could recite it" (Clark, interview, March 12, 2013). The former mission statement read:

Through international education, experience and community service, United World Colleges enables young people to become socially responsible citizens, politically and environmentally aware, and committed to the ideals of peace and justice, understanding and cooperation, and the implementation of these ideals through action and personal example (United World Colleges Magazine, April/May, 2002) 
Incredibly, $100 \%$ of the participants interviewed were able to recite the mission of UWC when asked. While some may have missed a few words or chose to paraphrase, all of them knew what it was and what UWC stood for. What these interviews revealed is that simplifying the mission statement is necessary for community members to understand and remember it, and moreover, that it has to be coupled with tangibility if it is going to be acted upon.

At UWC Costa Rica, a "competencies" system has been put in place. Several years ago, the school leadership and board worked on a plan to create tangible competencies that were going to ensure the campus worked towards mission alignment. These are: social responsibility, diversity, conflict transformation, sustainability, leadership, and healthy lifestyle. Students have to engage in activities in several of these areas. For example, they may choose to join the mediation program, which fulfills the conflict transformation competency and upholds UWC's mission of creating a more peaceful world. Students and alumni of this campus were interviewed about how the mission of UWC comes to life, and most often they mentioned the competencies program. In fact, of the twelve students and alumni interviewed from Costa Rica, 67\% (8 out of 12) mentioned an aspect of the competencies program directly when asked about the context of the mission of UWC.

Other UWC campuses have implemented tangible programs to help students understand, experience, and engage the mission; for example, Atlantic College in Wales created the "faculties program". These faculties are: Social Justice, Environment, Outdoor, and Global. Students choose one of these to focus on during their two years on campus, but they must also take time throughout their time on campus to engage the other faculties as well. $100 \%$ of the students interviewed on the Wales campus mentioned these faculties when asked about how they see the mission coming to life on their campus.

While each of the campuses has its own way of bringing the UWC mission to life, the systems put in place to make the mission tangible, things students can understand and engage on a daily basis, are what make mission fidelity attainable.

\section{Findings in the Context of Mission Literature}

The conceptual framework for this research study embeds itself in the literature on institutional mission and adopts the notion that there is a relationship between mission and outcome at UWC. However, the researcher sought a deeper understanding of what that relationship is and how it is operationalized. Studies indicate that "operationalization decisions and variable selection significantly influence the strength of mission statement performance" (Desmidt et al., 2011). This conceptual framework guides us to presume that students who attend UWC will have their behavior impacted in some way, shape, or form.

Some of the findings in this research study were in line with the current literature on mission. The contextual framework, which assumes a relationship between mission and behavior, was certainly a consistent theme in some of the research findings. UWC members are selected strategically, and both students and staff are chosen to uphold the mission of the organization. Mission literature posits that people can't be motivated if they don't feel a direct connection to their own values (Reilly, 2000). Mission statements are a cultural tool that guide people (Bart, 2007), and a mission helps to satisfy people's needs to be part of something "bigger" while producing something worthwhile (Pearce \& David, 1987). As noted in the findings, UWC members often join and stay at the organization for its mission and values. It moves them towards a greater goal.

Another finding of this research study in line with current literature on mission is the notion of simplicity and tangibility. Scholars note that the best mission statements are simple and to the point (Bart, 1998) and a mission statement has to be operational (Drucker, 1990). People need a reason for action and they need to understand not only the mission, but how to achieve it. In an effort to create simplicity and tangibility, UWC intentionally changed its mission to read in a clear context without complex language. In addition, it put an educational model in place to help the campuses understand how to make the mission concrete. The organization wanted each campus to have a guiding structure for how it was going to bring the mission to life. This strategy is crucial. "The more an agency aligns its mission attachment with its organizational components, the greater is its success in accomplishing its mission" (Colins \& Porras, 1996). If an organization presented a mission without actual links to implementation strategies, stakeholders would have very little direction (Leuthesser \& Kohli, 1997). This kind of tangibility has helped the campuses continue to shape and define their curricular and co-curricular programming, residential programs, and decision making around the physical infrastructure as highlighted in the previous chapter.

Finally, UWC attempts to create a visual representation of its mission on all of the campuses. Many aspects of the physical space embody the values of the organization. My observations confirmed the presence of the mission statement represented through the actual wording or other manifestations at all of the campuses. This practice is in 
line with Brinckerhoff, who suggests: "a mission statement needs to be visible everywhere in the organization, including staff personnel policies, staff orientation manuals, annual reports, strategic plans, and even in the screen saver on all of the individual employee computers" (Brinckerhoff, 2002).

\section{Analysis and Implications}

Mission driven organizations will certainly benefit from creating strategic alignment between their daily operations and the mission. The eight findings in this research study could help organizations implement the best practices and make decisions around resource allocation in an effort to maintain mission fidelity. Organizations interested in aligning all aspects of their organization with the mission should ask themselves:

1.1 How does the physical infrastructure represent our mission? What do we post on the walls, serve in our cafeteria, or display in our facility? Where do we display the mission so it is a constant reminder to everyone? What kind of decisions do we make around the physical space we inhabit, including the products we buy, the way we use space, and the things we display, that actually represent our mission?

1.2 What kind of orientation programs do we offer to new community members to help them understand and engage the mission? In addition, what kind of rituals and traditions do we put in place when people leave? If we want people to engage our mission, what traditions do we put in place to bring those to life?

1.3 How do we select people to become a part of our community? If mission indeed matters, what hiring or selection processes do we develop to ensure we invite individuals who are passionate about the mission of the organization?

1.4 If we are a school, is our curriculum in line with our mission? Is what students are learning central to the mission? How can we encourage teachers to bring mission-central topics into the classroom on a regular basis? How can we ensure that students don't just experience the mission through co-curricular life, but through their academic experiences as well?

1.5 If we are a residential school, how will our residential life program embody our mission? What intentional systems or processes can we put into place that reflects the mission of the institution? Given that our students are on campus 24 hours a day, how will we create further opportunities for them to engage the mission outside of the classroom and in the residence halls?

1.6 What kind of programming will we choose that best engages the mission of the institution? What programming choices will we create for strategic alignment between community members and organizational mission?

1.7 Are there creative ways to foster reflection opportunities for members of our community? How can we create a culture of reflection in our organization that encourages community members to engage the mission and constantly ask themselves how they are living up to it or aspiring to do so? What kind of rituals and traditions can we create around reflection to make this practice a part of the organizational culture?

1.8 The simpler and tangible we make the mission, the easier it will be for people to uphold it. Can we simplify our mission so that it is easier for community members to comprehend? In addition, what kind of tangible programs, procedures, or processes can we put in place to help community members understand, experience, and uphold the mission?

\section{Conclusion}

The United World Colleges is a complex global organization with thousands of moving parts, whose mission guides its existence. This study aimed to understand how an organization operationalizes its mission and socializes its constituents to support it, and found significantly intentional practices and systems in place at UWC towards this endeavor. The study found eight distinct themes that make a significant contribution to how the organization attempts to bring its mission to life. (1) The organization creates strategic entrance rituals, like orientation, as well as exit processes that help create and instill mission fidelity in its members. (2) The organization puts systems in place to ensure that students and staff are selected who are passionate about the mission and feel fidelity towards it. (3) The chosen curriculum is in line with the mission, and teachers make a commitment to bring mission-centric material into the classroom on a regular basis. (4) Mission is widely represented in the physical space. From the actual mission statement being visible to the artwork, promotional materials, and food displayed, the physicality of the campuses align with the organization's mission. (5) The programming and extracurricular activities offered throughout the organization are mission-centric and give members an opportunity to actually engage the mission. (6) The residential life program of the school is in line with the mission of the organization. The way students are housed and organized 
intentionally aligns with the conflict mediation aspects of the mission. (7) Giving community members the opportunity to reflect on the mission and how they aspire to live up to it instils a greater attachment to the mission. (8) The simplicity and tangibility of the UWC mission has helped members easily learn, recollect, and understand how to engage the mission.

These eight findings can help organizations think about how to set up their own programs, processes, rituals, and curricula that align with their mission and help its members understand how to best live up to its goals. This research study looked at how one organization attempts to do this. It is important for each organization to work with its members to implement systems that ensure the mission is operationalized on a daily basis. In the end "to state the idea without specifying the implementation is to communicate very little" (Leuthesser and Kohli, 1997).

\section{References}

Bart, C. K. (1998). Mission statement rationales and organizational alignment in the not-for-profit health sector. Health Care Management Review, 23(4), 56. https://doi.org/10.1097/00004010-199810000-00005

Bart, C. K. (2007). A comparative analysis of mission statement content in secular and faith-based hospitals. Journal of Intellectual Capital, 8(4), 682. https://doi.org/10.1108/14691930710830837

Boerema, A. (2006). An analysis of private school mission statements. Peabody Journal of Education, 81(1), 180. https://doi.org/10.1207/S15327930pje8101_8

Boerema, A. (2009). Does mission matter? An analysis of private school achievement differences. Journal of School Choice, 3, 112. https://doi.org/10.1080/15582150902996708

Branson, J. (2003). An evaluation of United World Colleges. London: University of London.

Brinckerhoff, P. C. (2002). Mission-based management (2nd ed.). Hoboken, NJ: John Wiley \& Sons.

Collins, J. C., \& Porras, J. I. (1996). Building your company's vision. Business Review, 74(5), 65.

Desmidt, S., Prinzie, A., \& Decramer, A. (2011). Looking for the value of mission statements: A meta-analysis of 20 years of research. Management Decision, 49(3). https://doi.org/10.1108/00251741111120806

Drucker, P. F. (1990). Managing the nonprofit organization (1st ed.). New York, NY: Harper Collins.

Golafshani, N. (2003). Understanding reliability and validity in qualitative research. The Qualitative Report, 8(4).

Gow, P. (2009). What should mission statements do? Independent School, 69, 24.

Hayden, M.C. (2006). Introduction to international education: international schools and their communities. Thousand Oaks, CA: Sage.

Hendrie, C. (1996). Principals seek to identify measures of school quality. Education Week, June 5.

Hirschfield, M. (2009). Mission impossible?. Independent School, 69, 32.

IB World. (2008). Enlightenment through understanding. Retrieved from http://www.ibo.org/ibworld/jan2008/enlightenment.cfm

Leuthesser, L., \& Kohli, C. (1997, May/June). Corporate identity: The role of mission statements. Business Horizons, 59. https://doi.org/10.1016/S0007-6813(97)90053-7

Olsen, W. (2004). Triangulation in social research: Qualitative and quantitative methods can really be mixed. Retrieved from http://www.ccsr.ac.uk/staff/Triangulation.pdf

Paull, M., Bouldville, I., \& Sitlington, H. (2013). Using sensemaking as a diagnostic tool in the analysis of qualitative data. The Qualitative Report, 18(54).

Pearce, J., \& David, F. (1987). Corporate mission statements: The bottom line. Academy of Management Executive, 1, 109. https://doi.org/10.5465/ame.1987.4275821

Peterson, A. (2003). Schools across frontiers: The story of the international baccalaureate and the United World Colleges (2nd ed.). Chicago, IL: Open Court.

Reilly, C. A., \& Pfeffer, J. (2000). Hidden value. Cambridge, MA: Harvard Business School Press.

Saldaña, J. (2013). The coding manual for qualitative researchers. London, UK: Sage Publications.

Tsumagari, M.I. (2010). The enduring effects of a United World College education as seen through a graduate's eyes. Journal of Research in International Education, 9(3). https://doi.org/10.1177/1475240910388916

Yin, R. (2003). Applications of case study research (2nd ed.). Thousand Oaks, CA: Sage Publications, Inc. 